\title{
Electrical Properties of Horizontal Array Capacitor Using Composite Organic Dielectric Layer of Impregnated Glass-Fiber Epoxy
}

\author{
Hwa-Sun Park $\mathbb{D}^{1},{ }^{1}$ Young-Il Na $\mathbb{D}^{1},{ }^{1}$ Sang-Min Lee $\mathbb{D}^{1},{ }^{1}$ Su-Jeong Suh ${ }^{D},{ }^{1}$ Yong-Soo Oh $\mathbb{D}^{1},{ }^{1}$ \\ Joon-kyun Lee $\mathbb{D},{ }^{2}$ Sang Gweon Kim, ${ }^{2}$ Sang-Woo Han $\mathbb{D}^{3},{ }^{3}$ Ho-Young Cha $\mathbb{D}^{,}{ }^{3}$ \\ and Jung-Rag Yoon (iD)
}

${ }^{1}$ Dept. Advanced Materials Science Engineering, Sungkyunkwan University, Suwon, Republic of Korea

${ }^{2}$ KITECH 143, Hanggaul-ro, Sangnok-gu, Ansan-si, Gyeonggi-do, Republic of Korea

${ }^{3}$ Dept. Electronic and Electrical Engineering, Hongik University, Seoul, Republic of Korea

${ }^{4}$ Red Center, Samwha Capacitor, Yongin-si, Gyeonggi-do, Republic of Korea

Correspondence should be addressed to Su-Jeong Suh; suhsj@skku.edu

Received 15 October 2019; Revised 2 January 2020; Accepted 13 January 2020; Published 27 April 2020

Guest Editor: Yiju Li

Copyright ( $\odot 2020$ Hwa-Sun Park et al. This is an open access article distributed under the Creative Commons Attribution License, which permits unrestricted use, distribution, and reproduction in any medium, provided the original work is properly cited.

We introduce a horizontal array capacitor with nine capacitances in a single body using an organic dielectric layer impregnated with glass fiber as a prepreg sheet. An organic solid horizontal array capacitor with a dielectric of prepreg materials of the epoxy type can implement the nine capacitances in a single body via a unique simple lamination and cutting process. We then investigate the basic electrical properties of a horizontal array capacitor. The organic solid array capacitors with five electrodes and four dielectrics are $\mathrm{Cu} / \mathrm{PPG}$ layer/Cu/PPG layer/Cu/PPG layer/Cu/PPG layer/Cu with a horizontal array structure. The size of a completed array capacitor is $2.85 \times 2.85 \mathrm{~mm}$. The height of the fabricated array capacitor in the vertical direction is $0.5 \mathrm{~mm}$, with nine capacitances possessing a series-type structure. The average capacitance value of $C_{1}, C_{2}, C_{3}$, and $C_{4}$ is $1.98 \mathrm{nF}$, and each tolerance has a value within $1 \%$ based on the average value. The temperature change rate in the capacitance maintains a nearly linear characteristic, but the rate of change tends to increase finely from $120^{\circ} \mathrm{C}$ or more. The capacitance values of $C_{5}, C_{6}$, and $C_{7}$ with the parallel circuit were measured according to the voltage. Impedance and ESR (equivalent series resistor) of $C_{1}$ were measured according to frequency and temperature.

\section{Introduction}

TDK CKC series capacitor arrays offer multiple multilayer ceramic chip capacitors (MLCCs) in a single package. TDK's unique design offers low crosstalk to truly yield separate individual capacitors in a $100 \mathrm{nF}$ single package. The array types are configured in 2-in-1 and 4-in-1 package styles [1]. SEMCO produce capacitor array (CAP, $100 \mathrm{nF}, 16 \mathrm{~V}, \pm 20 \%$, $\mathrm{X7R}, 0805$ ) has 2-in-1 and 4-in-1 package styles [2]. Array capacitors consist of multiple capacitors in a single body and are effective in reducing the time and cost of placement and circuit space. Several other companies also produce arraytype capacitors. The dielectrics in the array capacitor used here are fabricated from ceramic materials. Typically, ceramic loading, which is used as a dielectric, should be much lower than $50 \mathrm{vol} \%$ to successfully pass the high-temperature thermal stress reliability test. The dielectric properties of polymer-ceramic composites for embedded capacitors have been presented in a study on the optimization of ceramicpolymer films at a ceramic loading of $40 \mathrm{vol} \%$ to improve the embedded capacitance tolerance and electrical properties [3-5]. The effects of $\mathrm{BaTiO}_{3}$ powder on ceramic-polymer films and MLCC using the $\mathrm{BaTiO}_{3}$-based oxides have been widely adopted in the dielectric materials for various electronic components [6-9]. In this study, a research study is introduced wherein array capacitors are constructed using 
organic-type PPG (prepreg) instead of ceramic materials such as $\mathrm{BaTiO}_{3}$. Prepreg is an intermediate material for highstrength composites and is often used in sheet form. It is composed of a molding material impregnated with epoxy resin (MATRIX), specially mixed with reinforcing material carbon fiber, glass fiber, and aramid fiber, among others. High-strength, high-elasticity, and ultra-lightweight features are widely applied to sports, leisure, aerospace, automobile, robotics, and other fields that require high-performance materials. Prepreg-type epoxy is a superior material, with properties such as low weight, high strength, thermal shock resistance, excellent dimensional stability at high temperature, low coefficient of thermal expansion (CTE), chemical resistance, and corrosion resistance, compared to general organic-type epoxy [10-12]. The impregnated glass-fiber epoxy uses the energy-storing structures to make the composite capacitors and batteries [13]. PPG using GCU explored the preparation of glass fiber coir-reinforced unsaturated polyester resin hybrid (GCU) composites with a novel prepreg/press fabrication process. Flexural, impact, and thermomechanical properties of GCU composites were investigated [14]. Recently, various properties such as CNT were added to glass-fiber epoxy to measure the temperature characteristics [15].

We studied the fundamental properties of capacitances of the 6-in-1 array-type in a single body using only organic dielectrics in a previously published paper [16]. In this study, we introduce the temperature and RF characteristics of a horizontal array-type capacitor (9-in-1) with 9ea capacitance using an organic dielectric of a prepreg material instead of a dielectric prepared with conventional $\mathrm{BaTiO}_{3}$ powder. This study aims to confirm the applicability of this material to array capacitors based on the results obtained through the basic structure and experiments using a composite organic dielectric layer of impregnated glass-fiber epoxy. Consequently, array capacitors with a composite organic dielectric of prepreg can be applied to various electronic circuits to demonstrate the possibility of reducing the module size.

First, Figure 1 is the structure of a conventional ceramic array capacitor (MLLC) with four capacitors.

The cross section is composed of internal electrode $(\mathrm{Ni})$, ceramic dielectric $\left(\mathrm{BaTiO}_{3}\right)$, and external electrode $(\mathrm{Cu} / \mathrm{Ni} /$ $\mathrm{Sn})$. To increase the reliability ensuring the high capacitance in MLCCs, Ni electrodes with uniformity are very important. Consequently, homogeneous and continuous $\mathrm{Ni}$ electrode and dielectric layers could enable the high-voltage operation suppressing the leakage currents, dielectric breakdown, and degradation. In fabricating the MLCCs with high reliability, high density of $\mathrm{BaTiO}_{3}$ ceramic and continuous $\mathrm{Ni}$ electrode should be fulfilled simultaneously. To promote densification of $\mathrm{BaTiO}_{3}$-based MLCCs, nanoparticles were utilized or composition of $\mathrm{BaTiO}_{3}$ was intentionally modified with doping elements $[17,18]$.

In this study, the horizontal array capacitors with nine capacitances in a single body can be explained with the illustration in Figure 2. It consists of a series-type array structure of $\mathrm{Cu} / \mathrm{PPG}$ layer/Cu/PPG layer/Cu/PPG layer/Cu/PPG layer/ $\mathrm{Cu}$ connected to each other. It can have the structure of nine array capacitors, as shown in the following equation:

$$
\begin{aligned}
& C_{1}, C_{2}, C_{3}, C_{4}, \\
& \frac{1}{C_{5}}=\frac{1}{C_{1}}+\frac{1}{C_{2}}, \\
& \frac{1}{C_{6}}=\frac{1}{C_{1}}+\frac{1}{C_{2}}+\frac{1}{C_{3}}, \\
& \frac{1}{C_{7}}=\frac{1}{C_{1}}+\frac{1}{C_{2}}+\frac{1}{C_{3}}+\frac{1}{C_{4}}, \\
& \frac{1}{C_{8}}=\frac{1}{C_{2}}+\frac{1}{C_{3}}, \\
& \frac{1}{C_{9}}=\frac{1}{C_{3}}+\frac{1}{C_{4}} .
\end{aligned}
$$

Array capacitors with 9ea capacitance in a single body comprise five electrodes and four dielectrics, and the organic dielectric made of PPG materials between the metal $(\mathrm{Cu})$ and metal $(\mathrm{Cu})$ can form a capacitance. The capacitance between points A-B, B-C, C-D, D-E, H-J, H-K, H-L, I-K, and J-L are $C_{1}, C_{2}, C_{3}, C_{4}, C_{5}, C_{6}, C_{7}, C_{8}$, and $C_{9}$, respectively. If the organic dielectric material and thickness are made constant, the capacitance values of $C_{1}, C_{2}, C_{3}$, and $C_{4}$ will be the same. $C_{5}$ will have a series capacitance from $C_{1}$ and $C_{2}$, electrically connected in the series type as equation (1). $C_{6}$ can obtain a series capacitance value from $C_{1}, C_{2}$, and $C_{3}$ by electrically serial structures, as shown in equation (1). $C_{7}, C_{8}$, and $C_{9}$ can also be calculated using equation (1), as shown Figure 2. As we know, if the capacitors have an electrically series-type structure, the series capacitance value will be proportionally reduced using equation (1).

The implementation of the proposed horizontal array capacitor has several useful advantages if applied to an electronic circuit as shown in Table 1. First, it can reduce the size of the connection length and volume of the electronic circuit if several capacitors are configured in a single body. The reduced size of the electronic circuit can reduce the impedance value in a high-frequency environment. Second, if the capacitance value in the proposed array capacitor can be freely formed between electrodes, the serial and parallel circuits can be formed very easily. In this study, we proposed a unique solid array capacitor that can realize 9ea capacitance values in a single body through the structure background shown in Figure 1. Additionally, the experimental samples were prepared using a novel fabrication process and their electrical characteristics, such as voltage, temperature, and frequency, were analyzed.

\section{Experimental Method}

As shown in Figure 3, array capacitors with a series-type structure using PPG sheet in the horizontal direction can be manufactured as follows:

(1) The PPG used in this study serves as a dielectric layer in the capacitor, whose less thickness indicates a large capacitance value. A PPG sheet, a molding material impregnated with a specially 


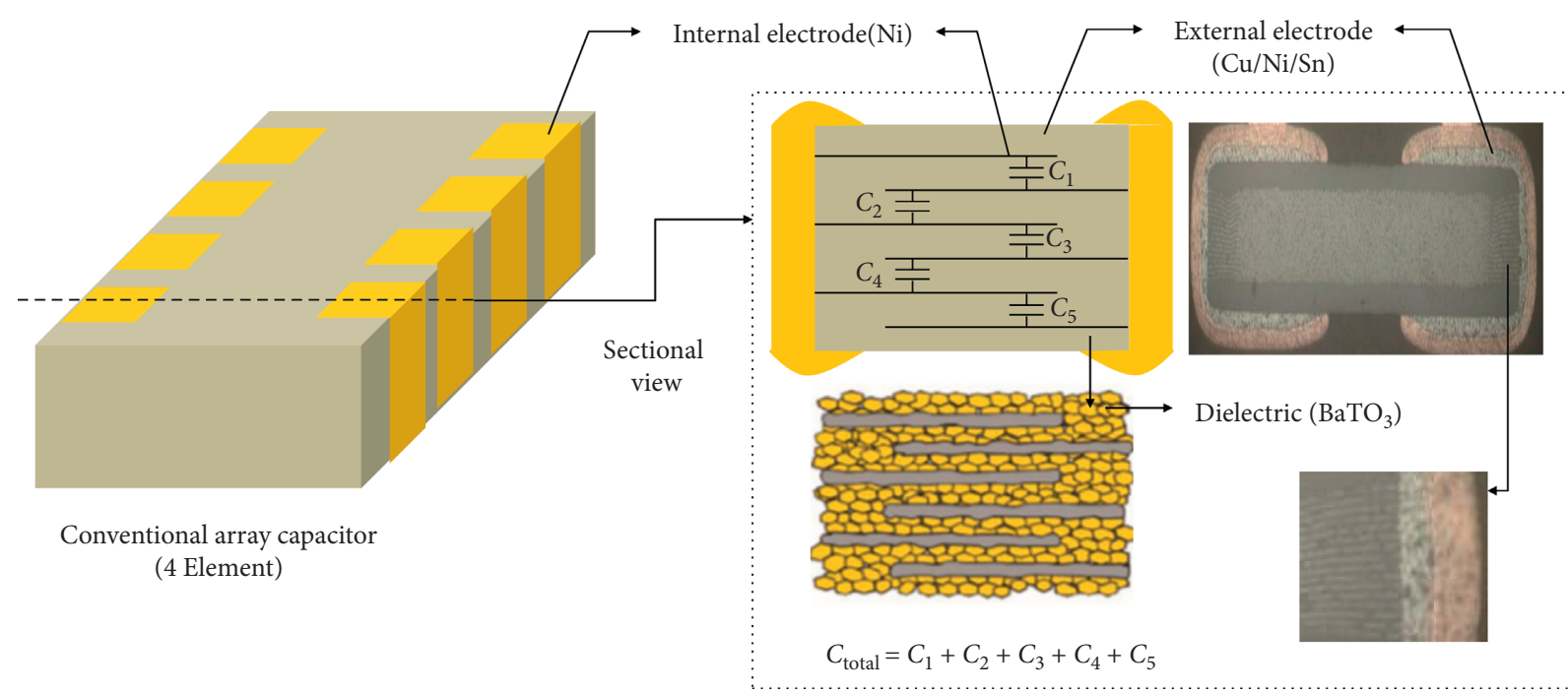

FIgURE 1: The structure of the conventional array capacitor.

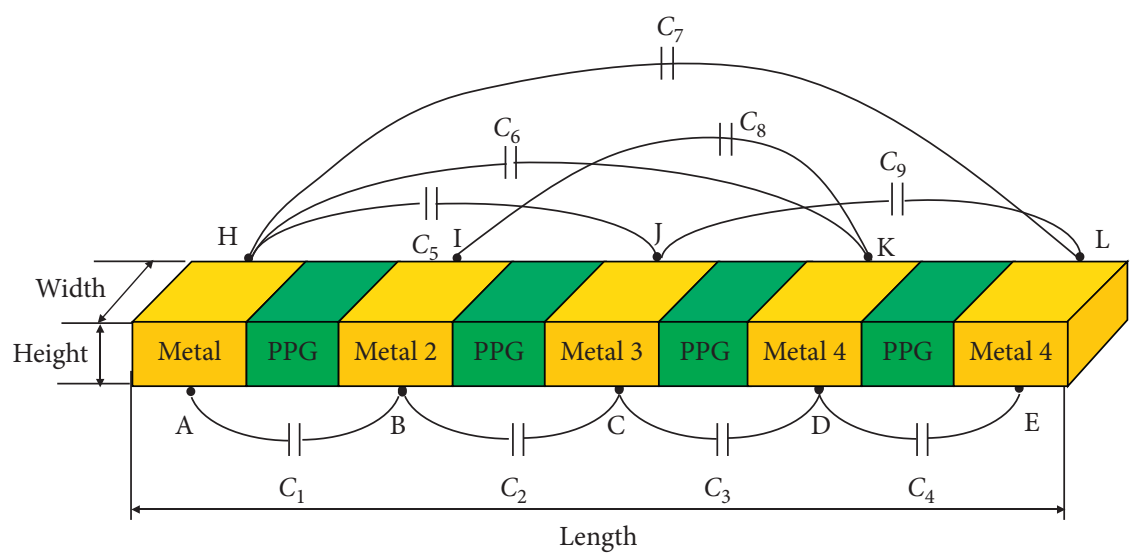

FIgURE 2: Application example of a horizontal array capacitor with 6 capacitors in single bodies.

TABle 1: The example of the decoupling capacitor using the structure shown in Figure 1.

\begin{tabular}{|c|c|c|c|c|c|c|c|c|}
\hline \multirow{2}{*}{\multicolumn{4}{|c|}{ The proposed array capacitor }} & \multirow{3}{*}{$\begin{array}{c}\text { Ground position } \\
\text { In case of ground } 4\end{array}$} & \multicolumn{4}{|c|}{ The example of circuit schematic } \\
\hline & & & & & \multirow{2}{*}{$\begin{array}{c}1 \text { point } \\
\frac{1}{I}\end{array}$} & \multirow{2}{*}{$\begin{array}{c}2 \text { points } \\
\stackrel{9}{=}\end{array}$} & \multirow{2}{*}{$\begin{array}{c}3 \text { points } \\
9\end{array}$} & \multirow{2}{*}{$\begin{array}{c}4 \text { points } \\
-\end{array}$} \\
\hline 1 & 2 & $\begin{array}{l}3 \\
0\end{array}$ & 4 & & & & & \\
\hline Metal & Metal & Metal & Metal & & 立 & \pm & $\mp$ & \\
\hline 1 & 2 & 3 & $\begin{array}{l}\frac{1}{4-2} \\
9\end{array}$ & In case of ground 2 & $\frac{1}{\bar{y}}$ & $\begin{array}{l}- \\
-\end{array}$ & i & $\stackrel{i}{2}$ \\
\hline Metal & Metal & Metal & Metal & & II & & $\frac{\bar{I}}{\bar{I}}$ & $\frac{ \pm}{ \pm}$ \\
\hline 1 & $=$ & & $\begin{array}{l}4 \\
9\end{array}$ & In case of ground 2 & & & i & \\
\hline Metal & Metal & Metal & Metal & & & & $I^{\prime}$ & \\
\hline 1 & $\overline{\bar{J}}$ & & 4 & In case of ground 2 & & & & \\
\hline Metal & Metal & Metal & Metal & & & & $\frac{ \pm}{J}$ & \\
\hline $\begin{array}{l}1 \\
9\end{array}$ & $\bar{\perp}$ & & $\overbrace{0}^{4}$ & No ground (parallel) & & & & \\
\hline Metal & Metal & Metal & Metal & & & & & \\
\hline
\end{tabular}




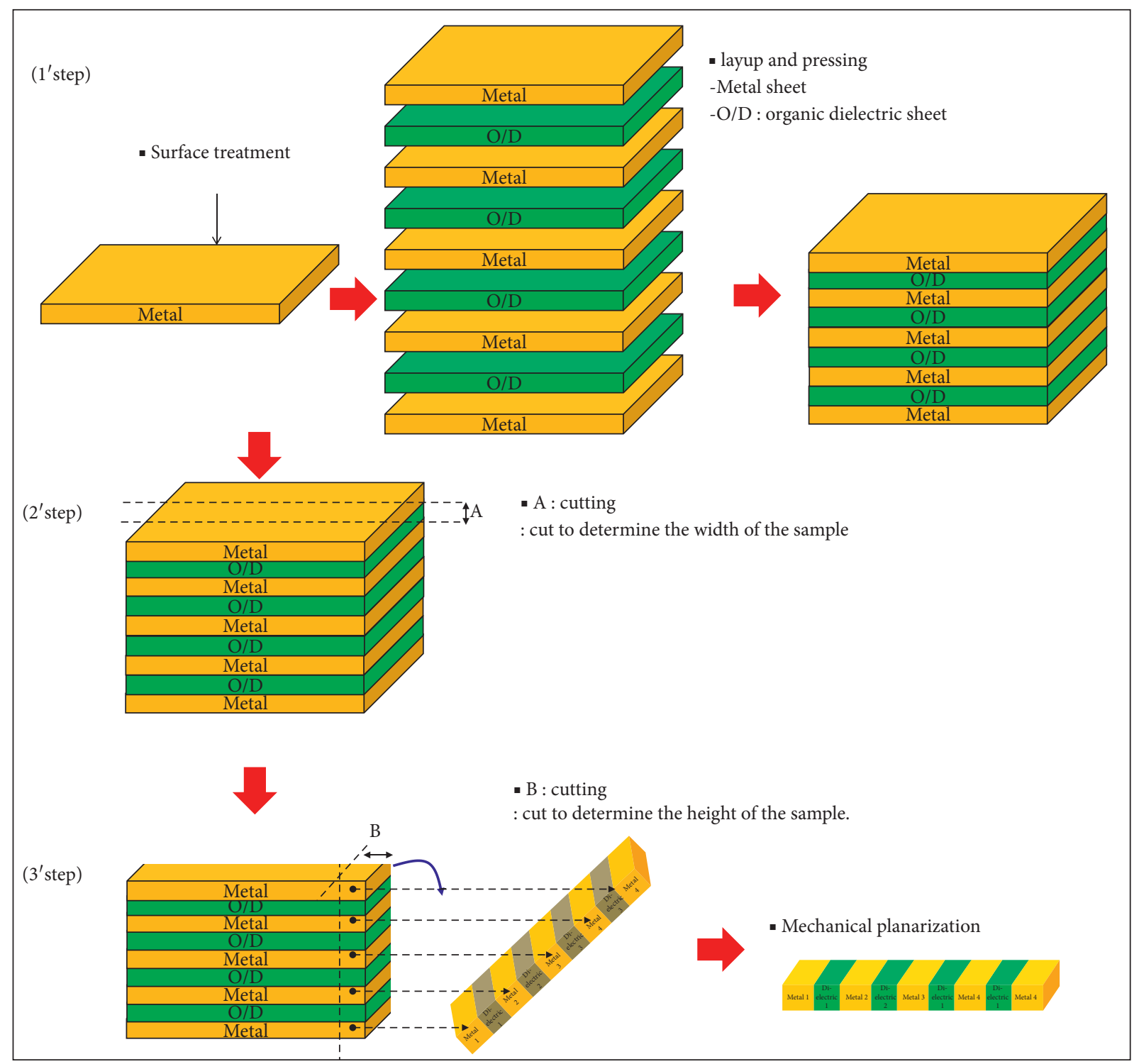

FIgURE 3: The fabrication method of the horizontal array capacitor with the PPG dielectric layer.

blended epoxy, and glass-fiber resin with a thickness of $60 \mu \mathrm{m}$ was used to form a dielectric layer between the $\mathrm{Cu}$ electrodes. PPG can be used as a dielectric material in a capacitor owing to its high strength, heat shock resistance, low CTE, chemical resistance, and corrosion resistance. Sheets with dimensions $100 \times 100 \mathrm{~mm}$ were formed between the $\mathrm{Cu}$ electrodes. The PPG sheet was laminated using the pressure/time/temperature of the equipment, simultaneously, and a pressed PPG sheet was formed with an approximate thickness of $50 \mu \mathrm{m}$ between the two $\mathrm{Cu}$ sheets. The PPG sheet contains the epoxy of the $\mathrm{B}$ stage (impregnated glass fiber). It has a resin flow of less than $2.5 \mathrm{~mm}$ and $65 \%$ content. During the lamination process, some amount of epoxy resin fell out and the resulting thickness was reduced to approximately $50 \mu \mathrm{m}$.
It is halogen-free, produces very low dust in the punching and cutting process, has low CTE in the $Z$ axis, and high solder ability. Currently, the dielectric constant of this material is approximately 4.5 6.9 at low frequency. PPG sheet materials should be developed to have excellent electrical properties, stable temperature characteristics, and high capacity at high frequencies.

(2) The top and bottom of the $\mathrm{Cu}$ sheet were cleaned. After laying down five $\mathrm{Cu}$ and four PPG sheets in order, they were pressed simultaneously using the lamination profiles (1'step).

(3) He pressed samples were cut using a mechanical diamond cutter for the predesigned size vertically by 2' 3' steps.

(4) The width of the proposed array capacitor was determined by the 2' step process, as illustrated in 


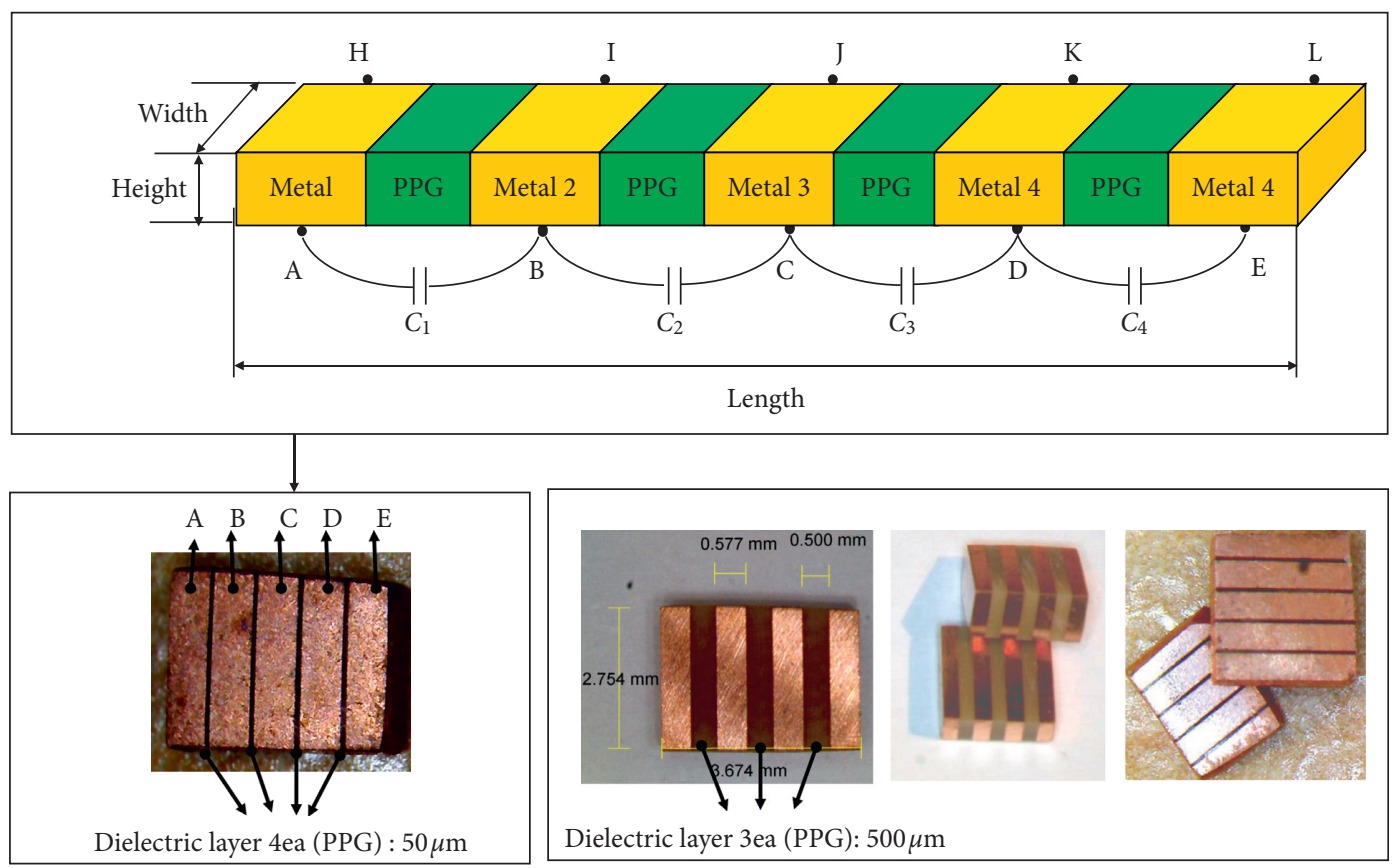

(a)

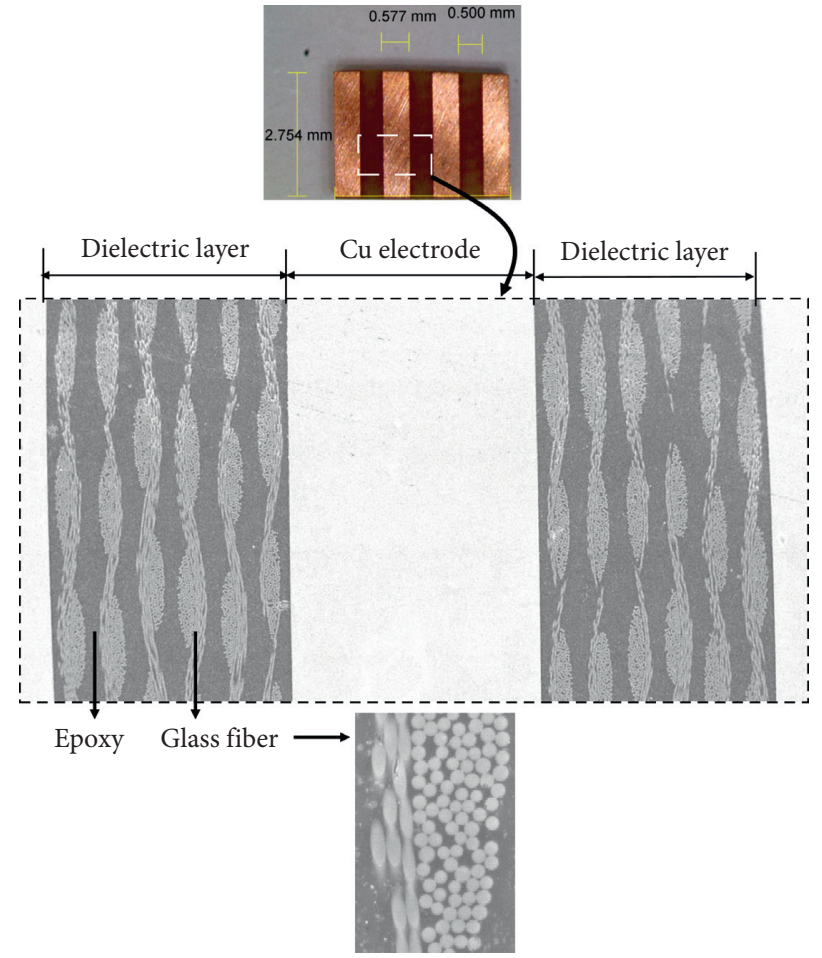

(b)

FIGURE 4: Fabricated horizontal array capacitor having (a) 9ea capacitances with five electrodes and four dielectrics and (b) an impregnated glass fiber of the epoxy as the dielectric.

Figure 3. First, it was cut to the size of a predesigned width. The sample prepared by the cutting process should be again cut through the 3'-step cutting process. The $3^{\prime}$-step process was conducted to determine the height using the predesigned size. After cutting, the sample was tilted sideways and placed on the floor. The array capacitor with nine capacitances, consisting of five electrodes and four dielectrics, can be fabricated using the sequence of the new process, as described above. The cut sample was finished using a mechanical flattening operation. 

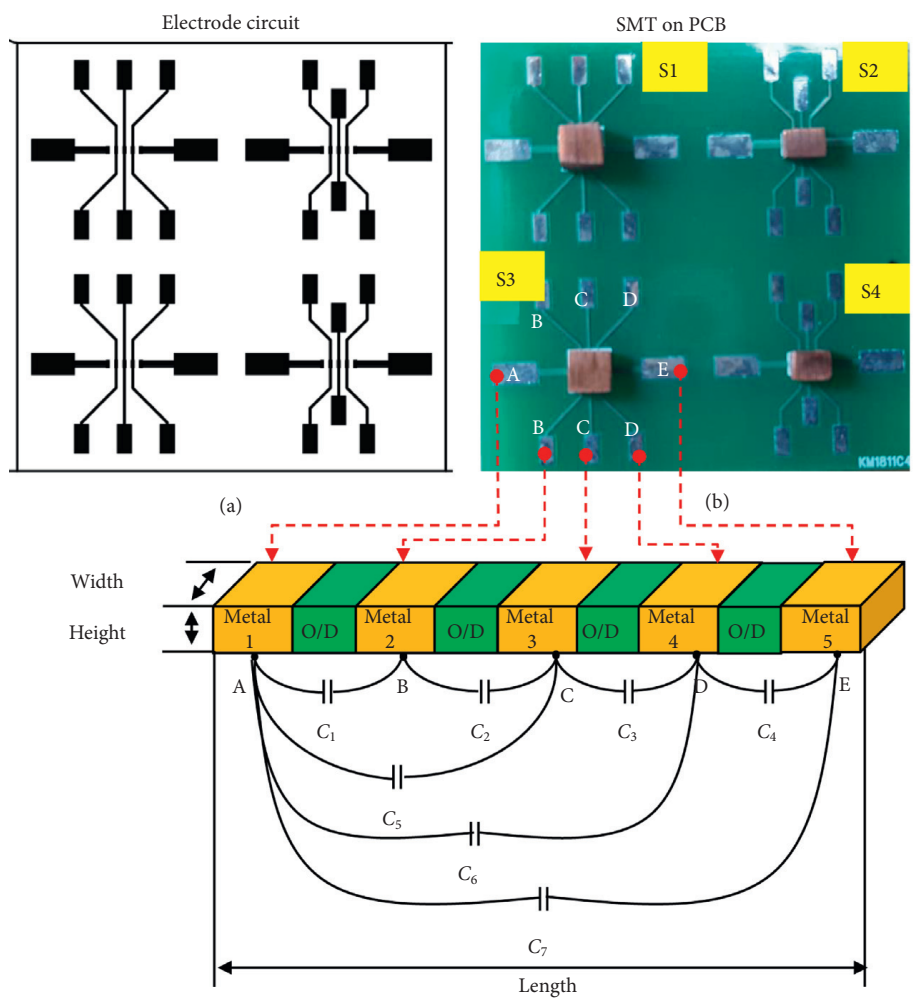

SMT on PCB

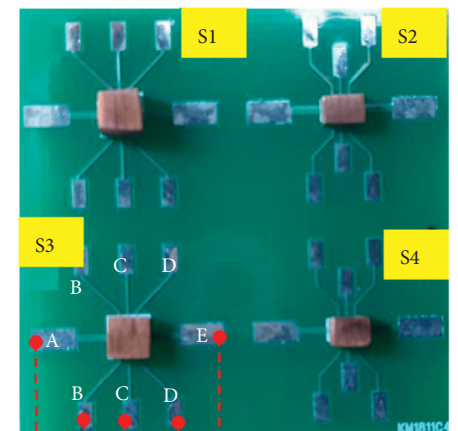

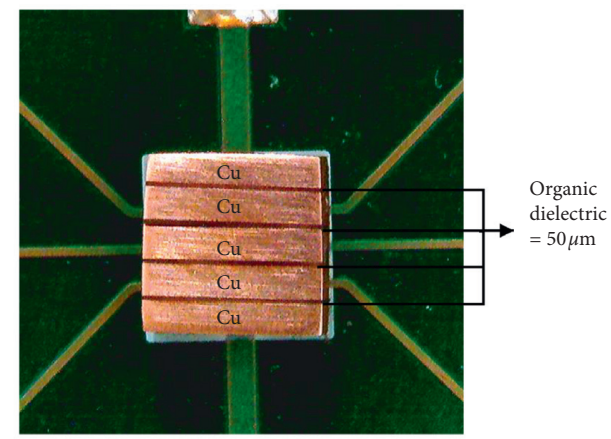

(c)

FIGURE 5: SMT of array capacitors on the PCB to measure the electrical properties.

Figure 4(a) illustrates a flat photo of a unique array capacitor fabricated using five electrodes and four dielectrics. A fabricated capacitor has a size of sample 1 $(2.754 \times 3.674 \mathrm{~mm})$ with four electrodes and three dielectrics and sample $2(2.85 \times 2.85 \mathrm{~m})$ has five electrodes and four dielectrics. The thickness of the electrode and dielectric at the plane is approximately $0.5 \mathrm{~mm}$. By increasing the number of $\mathrm{Cu}$ and PPG sheets, more horizontal array capacitors can be fabricated. Figure 4(b) shows a plane view of the synthesized epoxy impregnated with glass fiber, which acts as a dielectric between the electrodes. The microstructure of a fabricated horizontal array capacitor sample was characterized by scanning electron microscopy (JSM6360, Jeol). A single glass fiber with a diameter of $8 \mu \mathrm{m}$, comprising several pieces, was fabricated into one object. It was tied in a matrix form. Subsequently, one PPG sheet can be prepared by coating epoxy, which has high mechanical strength and can maintain high reliability in the process. The dielectric constant is low, but the rate of change in the temperature is fairly stable.

\section{Results}

Figure 5 shows that the fabricated samples $\left(S_{1}, S_{2}, S_{3}\right.$, and $\left.S_{4}\right)$ were soldered on the Printed Circuit Board to measure the electrical properties. The electrode circuit on the PCB was designed such that the array capacitor with five electrodes and four dielectrics was connected by soldering. The fabricated array capacitors $\left(S_{1}, S_{2}, S_{3}\right.$, and $\left.S_{4}\right)$ have different lengths and widths. The electrical properties of the array capacitors with four dielectrics between five electrodes were measured using an electrode pad at the A-E points for sample $S_{3}$ on PCB.

Figure 6 shows the electrical properties of capacitance/ impedance/ESR according to temperature and frequency from the measurement point of the fabricated sample $S_{3}$. As shown in Figure 6(a), $C_{1}(\mathrm{~A}-\mathrm{B}), C_{2}(\mathrm{~B}-\mathrm{C}), C_{3}(\mathrm{C}-\mathrm{D}), C_{4}(\mathrm{D}-$ $\mathrm{E}), C_{5}(\mathrm{~A}-\mathrm{C}), C_{6}(\mathrm{~A}-\mathrm{D})$, and $C_{7}(\mathrm{~A}-\mathrm{E})$ according to $\mathrm{DC}$ bias $(0-40 \mathrm{~V})$ were measured using a LCR meter (E4980A, Keysight Frequency $1 \mathrm{MHz}$, Level $1 \mathrm{~V}$ ) from each measurement point on the $\mathrm{PCB}$. Because the capacitance value of $C_{5}(\mathrm{~A}-\mathrm{C}), C_{6}(\mathrm{~A}-\mathrm{D})$, and $C_{7}(\mathrm{~A}-\mathrm{E})$ is a series circuit according to equation (1), it is expected to reduce by half. The measured average capacitance value of $C_{1}, C_{2}, C_{3}$, and $\mathrm{C}_{4}$, as shown in Figure 6(a), is $1.98 \mathrm{pF}$, and each tolerance based on the average value has a value within $1 \%$. Using the measured average values of $C_{1}$ and $C_{2}$, the calculated capacitance value of $C_{5}$ can be interpreted as $0.94 \mathrm{pF}$ but the actual measured value is $0.98 \mathrm{pF}$, which is approximately $4 \%$ tolerance. The measured value of $C_{6}$ was $0.65 \mathrm{pF}$, which corresponded to the value calculated by the serial circuit formula of $C_{1}, C_{2}$, and $C_{3}$, respectively. However, the measured value of $C_{7}$ was $0.38 \mathrm{pF}$, but the tolerance was $20 \%$ when compared to the calculated value. Essentially, the rate of change of capacitance according to the bias voltage is excellent within $1 \%$ in the case of $C_{5}$ and $C_{6}$. The DC bias voltage of this experiment measured the characteristics of capacitance at $40 \mathrm{~V}$. However, the BDV characteristics of the PPG sheet used as a dielectric material in this study can be satisfactory even above $200 \mathrm{~V}$. Figure $6(\mathrm{~b})$ shows the rate of change of capacitance with temperature at $C_{1}$ (A-B) point. The TCC (temperature-capacitance-characteristics) curves 


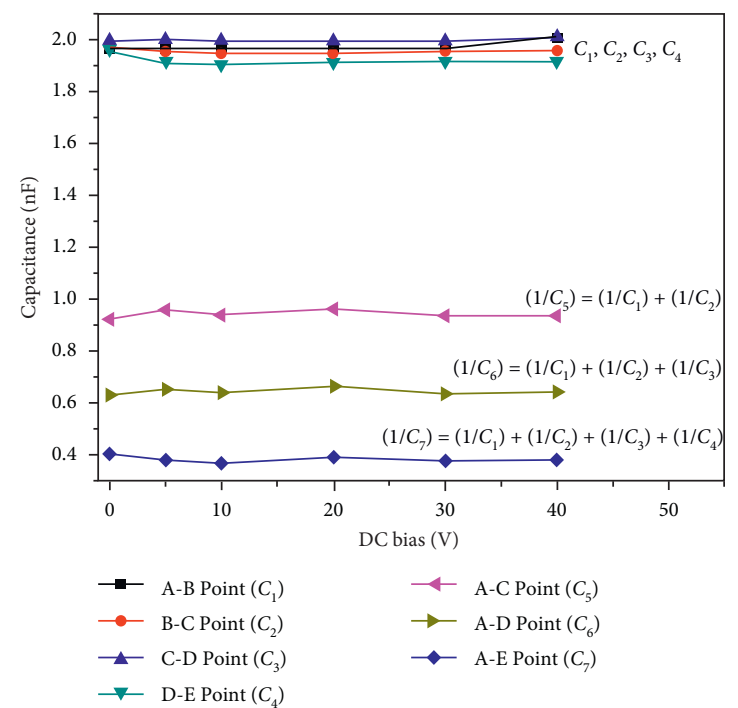

(a)

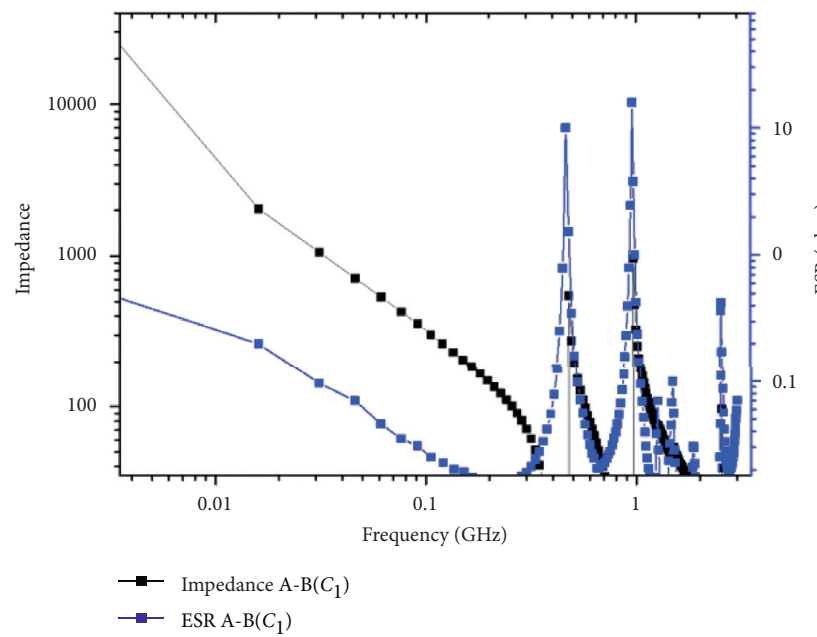

(c)

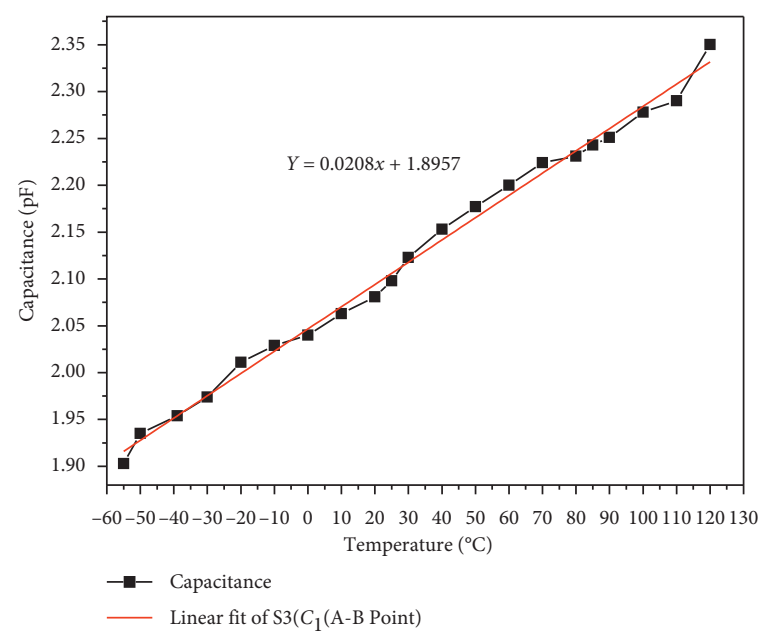

(b)

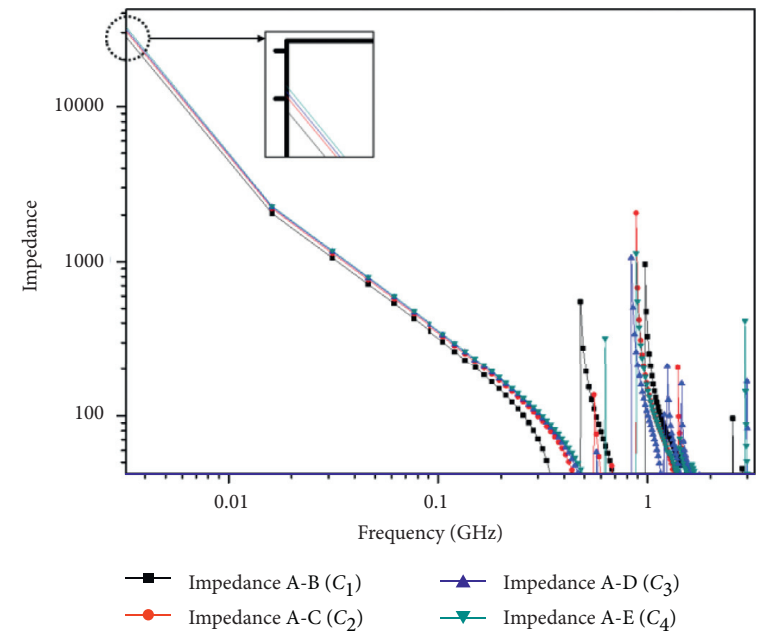

(d)

FIgURE 6: Electrical properties according to frequency. (a) Capacitance vs DC bias. (b) Capacitance vs temperature. (c) Impedance/ESR vs frequency @ $C_{1}$. (d) Impedance vs frequency @ $C_{1}, C_{2}, C_{3}, C_{4}$.

and capacitances were determined using a HP 4284A precision LCR meter (HP, USA) at a test voltage of $1 \mathrm{~V}$ and a frequency of $1 \mathrm{kHz}$. The range of temperature was measured from -55 to $120^{\circ} \mathrm{C}$. At $-55,25$, and $120^{\circ} \mathrm{C}$, the capacitance was $1.903,2.098$, and $2.35 \mathrm{pF}$, respectively. As shown in Figure 6(b), capacitance measurements were taken in the temperature range from -55 to $120^{\circ} \mathrm{C}$ placing the array capacitors in a temperature chamber (S\&A Inc., USA). The rate of change of capacitance maintains a nearly linear characteristic but it tends to increase finely from $120^{\circ} \mathrm{C}$ or more. The linear rate of change of capacitance according to temperature can also be used as a temperature sensor. The glass fiber impregnated in the epoxy has a low dielectric property but excellent temperature characteristics. It can serve as a sensor with an average of four temperature change distributions in one body. Here, the four capacitance change rates are $C_{1}(\mathrm{~A}-\mathrm{B}), C_{2}(\mathrm{~B}-\mathrm{C}), C_{3}(\mathrm{C}-\mathrm{D})$, and $C_{4}(\mathrm{D}-\mathrm{E})$. Each capacitance measured by temperature can more accurately analyze the temperature distribution in the measurement environment. Figures 6(c) and 6(d) demonstrate the impedance and ESR versus frequency using an RF impedance analyzer (E4991A, keysight, $1 \mathrm{MHz} 3 \mathrm{GHz}$ ) for $C_{1}$. It can be seen that the waveform of impedance and ESR have the same periodic characteristics versus frequency. The resonance frequency was measured at $0.38 \mathrm{GHz}$. Several peak points of the reflected impedance after the resonance frequency are the waveform reflected from each electrode. The ESR was measured to be $11 \mathrm{ohm}$ or less, and it was confirmed to increase at the position where the resonance frequency increased. If the characteristic values of the capacitors from $C_{1}$ to $C_{4}$ are known, similar electrical characteristics can be expected in the other capacitors $\left(C_{5}-C_{9}\right)$. Figure $6(\mathrm{~d})$ shows the impedance measurements from $C_{1}$ to $C_{4}$. It is evident that the impedance value increases from $C_{1}$ to $C_{4}$ because each measuring point has a different distance. Additionally, a higher frequency indicates greater fluctuations in the 
impedance value, which is expected to be resolved by forming a PCB circuit suitable for high-frequency measurements. Further research is required to fabricate array capacitors of very small size and good high-frequency characteristics.

\section{Conclusions}

In this study, we propose unique array capacitors with a series-type structure in the horizontal direction using PPG sheets. Dielectric layer uses the PPG sheet materials of the impregnated glass fiber. The proposed array capacitors consist of 9ea capacitance using five $\mathrm{Cu}$ and four PPG sheets. We created useful and unique array capacitors using simple and unique manufacturing processes. The purpose of this study is to confirm that it can be applied to capacitor arrays based on the results obtained through basic theories and experiments. Additionally, the linear rate of change of capacitance according to temperature can be used as a temperature sensor. The electrical properties of the temperature sensor require further examination and analysis and are still under study. The results of the electrical properties can be applied to electronic circuits to demonstrate the possibility of reducing the size and noise of the module. The new manufacturing process described above is suitable for simple, cost-effective characteristics of organic materials when optimizing for the sophisticated cutting technology. In future, our research direction is to design a small-sized thinarray capacitor using high-capacity organic sheets as a composite dielectric layer of the impregnated glass-fiber epoxy material with reliability.

\section{Data Availability}

The authors declare that the data supporting the findings of this study are available within the article.

\section{Conflicts of Interest}

The authors declare that they have no conflicts of interest.

\section{Acknowledgments}

This research was supported by the Basic Science Research Program through the National Research Foundation of Korea (NRF), funded by the Ministry of Education (NRF2016R1A6A3A11931569). This study was supported by the GRRC program of Gyeonggi Province (GRRC Sungkyunkwan 2017-B02: Development of MEMS-based ultrathin \& ultra-thin temperature/humidity/pressure convergence environment sensor), funded by the Material \& Process Platform for Convergence Sensors.

\section{References}

[1] CKC Series: Array Capacitor, http://www.TDK.com.

[2] CAP Array, http://www.samsungsem.com.

[3] J. W. Kim, H. S. Park, S. C. Lee, Y. K. Chung, S. M. Choi, and S. Yi, "Development of lamination process for chip-in-substrates," in Proceedings of the International Conference on
Electronic Materials and Packaging (EMAP), pp. 1-6, Daejeon, Korea, November 2007.

[4] H.-S. Park, Y. Na, H. J. Choi, S.-J. Suh, D.-H. Baek, and J.-R. Yoon, "Electrical properties of $\mathrm{BaTiO}_{3}$-based 0603/0.1 $\mu \mathrm{f} /$ $0.3 \mathrm{~mm}$ ceramics decoupling capacitor for embedding in the PCB of $10 \mathrm{G}$ RF transceiver module," Journal of Electron Engineering Technology, vol. 13, no. 4, 2018.

[5] L. Qi, B. I. Lee, S. Chen, W. D. Samuels, and G. J. Exarhos, "High-dielectric-constant silver-epoxy composites as embedded dielectrics," Advanced Materials, vol. 17, no. 14, pp. 1777-1781, 2005.

[6] X.-H. Wang, R.-Z. Chen, Z.-L. Gui, and L.-T. Li, "The grain size effect on dielectric properties of $\mathrm{BaTiO}_{3}$ based ceramics," Materials Science and Engineering: B, vol. 99, no. 1-3, pp. 199-202, 2003.

[7] J.-R. Yoon, J.-W. Han, K.-M. Lee, and H.-Y. Lee, "Dielectric properties of polymer-ceramic composites for embedded capacitors," Transaction on Electrical and Electronic Materials, vol. 10, no. 4, pp. 116-120, 2009.

[8] J.-R. Yoon, "Electrical properties of Dy-doped $\mathrm{BaTiO}_{3}$-based ceramics for MLCC," Journal of Ceramic Processing Research, vol. 16, no. 5, pp. 495-498, 2015.

[9] C. Pithan, D. Hennings, and R. Waser, "Progress in the synthesis of nanocrystalline $\mathrm{BaTiO}_{3}$ powders for MLCC," International Journal of Applied Ceramic Technology, vol. 2, no. 1, pp. 1-14, 2005.

[10] P. K. Vallittu and C. Sevelius, "Resin-bonded, glass fiberreinforced composite fixed partial dentures: a clinical study," The Journal of Prosthetic Dentistry, vol. 84, no. 4, pp. 413-418, 2000.

[11] M. Weinhold and G. Yen, "How advanced low coefficient of thermal expansion (CTE) laminates and prepregs can improve the reliability of printed circuit boards (PCBs)," Circuit World, vol. 29, no. 1, pp. 24-31, 2003.

[12] D. Patil and V. N. Chalwa, "Mechanical property of glass fiber reinforcement epoxy composites," International Journal of Scientific Engineering and Research, vol. 1, no. 4, 2013.

[13] D. J. O’Brien, D. M. Baechle, and E. D. Wetzel, "Design and performance of multifunctional structural composite capacitors," Journal of Composite Materials, vol. 45, no. 26, pp. 2797-2809, 2011.

[14] F. Cheng, Y. Hu, and J. Yuan, "Preparation and characterization of glass fiber-coir hybrid composites by a novel and facile prepreg/press process," Fibers and Polymers, vol. 15, no. 8, pp. 1715-1721, 2014.

[15] A. S. Rahman, V. Rangari, and S. A. K. Jeelani, "Thermal and mechanical properties of woven glass fiber reinforced epoxy composites with carbon nanotubes grown in-situ," The International Journal of Engineering and Science, vol. 4, no. 12, pp. 54-61, 2015.

[16] H.-S. Park, Y.-I. Na, H.-J. Choi et al., "Electrical properties of a unique solid array capacitor with 6 capacitance consisting of 4 electrodes and 3 organic dielectrics in single body," AIP Conference Proceedings, vol. 1981, no. 1, 2018.

[17] C. S. Choi, K. S. Kim, D. H. Rhie, J. R. Yoon, and J. R. Yoon, "The effects of $\left(\mathrm{Ba}_{0.4} \mathrm{Ca}_{0.6}\right) \mathrm{SiO}_{3}$ nano spheroidization glass additives on the microstructure and microwave dielectric properties of $\mathrm{Ba}\left(\mathrm{Zn}_{1 / 3} \mathrm{Ta}_{2 / 3}\right) \mathrm{O}_{3}$ Ceramics," Journal of Electrical Engineering and Technology, vol. 9, no. 5, pp. 1719-1723, 2014.

[18] J.-R. Yoon, B. H. Moon, H. Y. Lee, D. Y. Jeong, and D. H. Rhie, "Design and analysis of electrical properties of a multilayer ceramic capacitor module for DC-link of hybrid electric vehicles," Journal of Electrical Engineering and Technology, vol. 8, no. 4, pp. 808-812, 2013. 